\title{
Concentrado proteico do soro melhora a qualidade sensorial de sobremesa láctea diet
}

\author{
Whey protein concentrate improves the sensory quality of free-fat dairy desserts
}

\author{
Márcia Cristina Teixeira Ribeiro Vidigal ${ }^{\mathrm{I}}$ Valéria Paula Rodrigues Minim $^{\mathrm{I}^{*}}$ Elaine Ceresino Berger \\ Afonso Mota Ramos ${ }^{I}$ Luis Antonio Minim
}

\section{RESUMO}

\begin{abstract}
Alimentos isentos ou de baixo nível de gordura constituem um desafio para a indústria de alimentos. Nesse contexto, este trabalho teve como objetivo estudar o efeito da adição de concentrado proteico de soro (CPS) nas características sensoriais e aceitabilidade de sobremesas lácteas sem gordura. Quatro formulações foram desenvolvidas com diferentes concentrações de CPS (0\%, 1,5\%, 3,0\% e 4,5\% $\left.\mathrm{m} \mathrm{v}^{-1}\right)$ e caracterizadas sensorialmente por meio da Análise Descritiva. A aceitabilidade das formulações foi avaliada por 94 consumidores que utilizaram escala hedônica de nove pontos. As sobremesas foram caracterizadas por oito atributos sensoriais: cor, firmeza, resistência ao corte, brilho, consistência, gomosidade, aroma e sabor de baunilha. As formulações contendo 3,0 e 4,5\% de CPS apresentaram maior intensidade de todos os atributos sensoriais. A adição de CPS foi efetiva na composição da textura das sobremesas lácteas diet, além de realçar a cor, sabor e aroma do produto. As formulações contendo 1,5 e 3,0\% de CPS foram as mais aceitas, evidenciando que a utilização do CPS nessas concentrações favoreceu a aceitabilidade do produto, proporcionando características sensoriais agradáveis aos consumidores.
\end{abstract}

Palavras-chave: aceitabilidade, características sensoriais, alimento sem gordura.

\begin{abstract}
Foods free or low-fat constituted are a challenge for the food industry. Thus, the objective of this research was to study the effect of the addition of whey protein concentrate (WPC) in the sensory profile and acceptability of dairy desserts free-fat. Four formulations had been developed with different WPC concentrations $(0 \%, 1.5 \%, 3.0 \%$ or $4.5 \%$, mass $\%)$ and sensory characterized by Descriptive Analysis. The acceptability of the formulations was evaluated by 94 consumers who had
\end{abstract}

used the nine-point hedonic scale. Dairy desserts were characterized by eight sensory attributes: color, firmness, resistance to cut, brightness, thickness, gumminess, aroma and vanilla flavor. The formulations containing 3.0 and $4.5 \%$ of WPC presented greater intensity of all the attributes. The addition of WPC was effective in the composition of the texture of freefat dairy desserts and enhances color, flavor and aroma of the product. The formulations with 1.5 and 3.0\% WPC had been most accepted, showing that the use of WPC in these concentrations favored the acceptability of the product, providing pleasant sensory characteristics to consumers.

Key words: acceptability, sensory characterization, free-fat food.

\section{INTRODUÇÃO}

Nas últimas décadas, tem-se observado um interesse no desenvolvimento de produtos com baixos teores de gordura ou sem gordura, em resposta à crescente demanda dos consumidores. Porém, a formulação desses alimentos constitui um grande problema para a indústria de alimentos, já que a gordura possui múltiplas funções, afetando a textura, aparência, sabor e aroma do produto (GONZÁLEZ-TOMÁS et al., 2008). Sendo assim, é importante entender como as mudanças na formulação de um alimento podem afetar suas características. $\mathrm{O}$ uso de concentrado proteico de soro (CPS) em produtos lácteos como substituto de gordura seria uma alternativa para manter importantes propriedades sensoriais, tornando o produto mais atrativo ao consumidor.

'Departamento de Tecnologia de Alimentos, Universidade Federal de Viçosa (UFV), Av. Peter Henry Rolfs, s/n., 36570-000,

Viçosa, MG, Brasil. E-mail: vprm@ufv.br. *Autor para correspondência. 
O CPS tem se mostrado um insumo interessante devido às suas propriedades funcionais, como geleificação, aumento de viscosidade, além de possuir apelo nutricional, uma vez que apresenta elevada concentração de proteínas de alto valor biológico. A funcionalidade das proteínas do soro está associada à sua composição e ao seu grau de desnaturação (LIZARRAGA et al., 2006). Além disso, constitui uma forma de aproveitamento do soro resultante das indústrias de laticínios que tem sido, na sua maioria, subutilizado, sendo a sua disposição final um dos maiores problemas enfrentados por grande parte das indústrias de laticínios (KAPOOR \& METZGER, 2004).

Ultimamente, a comercialização de sobremesas lácteas prontas para consumo tem apresentado considerável crescimento. Os ingredientes inovadores e os sistemas tecnológicos aplicados nas indústrias de laticínios têm proporcionado novas alternativas às sobremesas clássicas feitas em casa, permitindo a produção de sobremesas com novos sabores, com maior digestibilidade e maior valor nutritivo (NIKAEDO et al., 2004). Seu valor nutricional e suas características sensoriais favorecem o consumo por grupos de consumidores como crianças e idosos (TÁRREGA \& COSTELL, 2007).

Nesse contexto, este trabalho teve como objetivo estudar o efeito da adição de CPS nas características sensoriais e aceitabilidade de sobremesas lácteas tipo flan sem gordura.

\section{MATERIAL E MÉTODOS}

Elaboração da sobremesa

A sobremesa láctea sem gordura foi produzida no Laboratório de Propriedades Tecnológicas e Sensoriais dos Alimentos do Departamento de Tecnologia de Alimentos da Universidade Federal de Viçosa. Quatro formulações de sobremesa láctea tipo flan (Controle, CPS1,5, CPS3,0 e CPS4,5) foram preparadas com diferentes concentrações de CPS $\left(0 \%, 1,5 \%, 3,0 \%\right.$ e 4,5\% $\mathrm{m} \mathrm{v}^{-1}$, respectivamente). As concentrações de açúcar $\left(12 \% \mathrm{~m} \mathrm{v}^{-1}\right)$, leite em pó desnatado $\left(10 \% \mathrm{~m} \mathrm{v}^{-1}\right)$, amido de milho (5\% $\left.\mathrm{m} \mathrm{v}^{-1}\right)$, aroma de baunilha $\left(0,25 \% \mathrm{~m} \mathrm{v}^{-1}\right)$, k-carragena $\left(0,02 \% \mathrm{~m} \mathrm{v}^{-1}\right)$ foram fixadas. Os ingredientes sólidos foram pesados, misturados na forma seca e dissolvidos em água à temperatura de $40^{\circ} \mathrm{C}$. As sobremesas lácteas foram aquecidas sob agitação constante por 18 minutos até a temperatura de $90^{\circ} \mathrm{C} \pm 2^{\circ} \mathrm{C}$. Em seguida, foi adicionado aroma sob agitação por mais 2 minutos. As amostras foram acondicionadas em potes plásticos e armazenadas sob refrigeração $\left(10^{\circ} \mathrm{C} \pm 2^{\circ} \mathrm{C}\right)$, por aproximadamente 20 horas.
Análise Descritiva

A caracterização sensorial das formulações foi determinada por meio da Análise Descritiva por uma equipe treinada. Em todas as etapas, as amostras foram desenformadas em pratos descartáveis e servidas à temperatura de refrigeração.

Recrutamento dos julgadores

Foram distribuídos 50 questionários de recrutamento aos funcionários, estudantes de graduação e pós-graduação da Universidade Federal de Viçosa. Foram recrutados para a realização da préseleção, os candidatos que apresentaram disponibilidade de tempo, afinidade pelo produto, habilidade em trabalhar com escala não-estruturada, conhecimento sobre termos descritivos e condições de saúde que não comprometessem as análises.

Pré-seleção dos julgadores

Para avaliar a capacidade de discriminação sensorial dos candidatos, uma série de quatro testes de diferença global (teste triangular) foi aplicada. $\mathrm{O}$ critério para seleção foi o acerto de $75 \%$ dos testes, conforme recomendado por MEILGAARD et al. (2006). As formulações CPS1,5 e CPS3,0 foram utilizadas na série de testes de diferença. Em testes preliminares, essas formulações apresentaram diferença significativa $(\mathrm{P}<0,05)$ entre si.

Levantamento dos termos descritivos e definição do material de referência

O desenvolvimento da terminologia descritiva foi realizado por 19 julgadores préselecionados. Com auxílio de uma lista prévia de termos descritivos para sobremesas lácteas, obtidos de DE WIJK et al. (2006) e, sob supervisão de um moderador, os atributos que caracterizam as amostras foram determinados. A lista definitiva de avaliação foi formada pelo consenso entre os julgadores. Em sessões posteriores, foram definidos os materiais de referência que representam os extremos na escala não estruturada de nove centímetros e uma lista com os atributos, definições e padrões de referência para a sobremesa foi confeccionada (Tabela 1).

Treinamento e seleção dos julgadores

Foram realizadas várias sessões de treinamento, nas quais foram apresentados a definição para cada atributo e os padrões de referência. Os julgadores foram orientados a ler e compreender a definição de cada atributo e, em seguida, provar e memorizar os padrões. Após o treinamento, foi realizado um teste preliminar visando à seleção final dos 
Tabela 1 - Atributos, definições e padrões de referência para as sobremesas lácteas diet tipo flan.

\begin{tabular}{|c|c|c|}
\hline Termos descritivos & Definição & Padrão/Extremos da escala \\
\hline Brilho & $\begin{array}{l}\text { Intensidade de luz refletida no produto, contrário } \\
\text { de opaco. }\end{array}$ & $\begin{array}{l}\text { Fraco: sobremesa láctea com } 12 \% \text { de açúcar, } 10 \% \text { de } \\
\text { leite em pó desnatado, } 2,5 \% \text { aroma de baunilha, } 0,02 \% \\
\text { k-carragena e } 7 \% \text { de amido (R1). } \\
\text { Forte: Sobremesa láctea com } 12 \% \text { de açúcar, } 10 \% \text { de } \\
\text { leite em pó desnatado, } 0,25 \% \text { aroma de baunilha, } 0,02 \% \\
\text { k-carragena, } 5 \% \text { de amido e } 6 \% \text { de CPS (R2). }\end{array}$ \\
\hline Cor & Intensidade da cor amarela. & $\begin{array}{l}\text { Fraco: R1 } \\
\text { Forte: R2 }\end{array}$ \\
\hline Firmeza & $\begin{array}{l}\text { Quantidade de deformação provocada pela } \\
\text { compressão de uma colher sobre o produto antes } \\
\text { de ocorrer o corte (ISO 11036:1994). }\end{array}$ & $\begin{array}{l}\text { Fraco: controle } \\
\text { Forte: R2 }\end{array}$ \\
\hline Resistência ao corte & $\begin{array}{l}\text { Força necessária para provocar certa deformação } \\
\text { observada na colher (ISO 11036:1994). }\end{array}$ & $\begin{array}{l}\text { Fraco: controle } \\
\text { Forte: R2 }\end{array}$ \\
\hline Aroma de baunilha & Intensidade de aroma característico de baunilha. & $\begin{array}{l}\text { Fraco: sobremesa láctea com } 12 \% \text { de açúcar, } 10 \% \text { de } \\
\text { leite em pó desnatado, } 0,02 \% \mathrm{k} \text {-carragena, } 5 \% \text { de amido } \\
\text { e } 0,15 \% \text { aroma de baunilha (R3). } \\
\text { Forte: sobremesa láctea com } 12 \% \text { de açúcar, } 10 \% \text { de } \\
\text { leite em pó desnatado, } 0,02 \% \text { k-carragena, } 5 \% \text { de } \\
\text { amido, } 4,5 \% \text { de CPS e } 0,35 \% \text { aroma de baunilha (R4). }\end{array}$ \\
\hline Consistência & $\begin{array}{l}\text { Representa a espessura do alimento na boca } \\
\text { depois de ele ter sido comprimido para cima e } \\
\text { para baixo por movimento da língua contra o } \\
\text { palato (ISO 11036:1994). }\end{array}$ & $\begin{array}{l}\text { Fraco: controle } \\
\text { Forte: } 22\end{array}$ \\
\hline Gomosidade & $\begin{array}{l}\text { Esforço requerido para desintegrar um produto. } \\
\text { Quantidade de manipulação do alimento na } \\
\text { língua contra o palato antes do alimento se } \\
\text { desintegrar (ISO 11036:1994). }\end{array}$ & $\begin{array}{l}\text { Fraco: controle } \\
\text { Forte: R2 }\end{array}$ \\
\hline Sabor de baunilha & Intensidade de sabor característico de baunilha. & $\begin{array}{l}\text { Fraco: R3 } \\
\text { Forte: R4 }\end{array}$ \\
\hline
\end{tabular}

julgadores. As formulações controle e CPS4,5 foram apresentadas aos julgadores na mesma sessão, em três repetições, utilizando a ficha definitiva. Os julgadores foram avaliados de acordo com seu poder de discriminação e repetibilidade. Foram realizadas análises de variância (ANOVA) com duas fontes de variação (amostra e repetição) por atributo para cada julgador. Foram selecionados, para a etapa final, os julgadores que apresentaram probabilidade de $\mathrm{F}_{\text {AMOSTRA }} \leq 0,50 \mathrm{e}$ probabilidade de $\mathrm{F}_{\text {REPETIÇÃO }} \geq 0,05$ em todos os atributos avaliados.

Avaliação das amostras

As quatro formulações de sobremesa láctea sem gordura codificadas com três dígitos aleatórios foram apresentadas em cabines individuais com luz branca, à temperatura de refrigeração $\left(10^{\circ} \mathrm{C} \pm 1^{\circ} \mathrm{C}\right)$, aos nove julgadores selecionados. As quatro formulações foram avaliadas usando delineamento em blocos completos casualizados (COCHRAN \& COX, 1981) com três repetições. As amostras foram servidas aos julgadores que receberam a ficha de avaliação (escala não estruturada de nove centímetros), bem como a lista de definições de atributos sensoriais.

\section{Aceitabilidade sensorial}

A aceitabilidade sensorial das quatro formulações em relação à textura e impressão global foi avaliada por 94 consumidores, utilizando escala 
hedônica de nove pontos (1 - "desgostei extremamente" e 9 - "gostei extremamente"). As amostras foram desenformadas e servidas aos consumidores de forma monádica, à temperatura de refrigeração $\left(10^{\circ} \mathrm{C} \pm 1^{\circ} \mathrm{C}\right)$, em cabines individuais, sob luz branca.

Análise estatística

A avaliação dos resultados da caracterização sensorial foi realizada por meio da análise de variância (ANOVA), em nível de 5\% de significância, com as fontes de variação amostra, julgador e interação julgador*amostra para cada atributo. No caso de uma amostra apresentar interação julgador*amostra significativa, o efeito principal (amostras) foi novamente calculado usando o quadrado médio (QM) da interação como denominador, conforme recomendado por STONE \& SIDEL (1993). Os resultados foram também avaliados por meio da Análise de Componentes Principais (ACP).

A análise de resultados da aceitabilidade sensorial foi feita por meio do Mapa de Preferência Interno (MDPREF) (MINIM, 2010).

As análises estatísticas foram realizadas utilizando-se o programa estatístico SAS (Statistical Analysis System), versão 9.1, licenciado para Universidade Federal de Viçosa.

\section{RESULTADOS E DISCUSSÃO}

\section{Análise Descritiva}

As sobremesas foram caracterizadas por oito atributos sensoriais: cor, firmeza, resistência ao corte, brilho, consistência, gomosidade, aroma e sabor de baunilha. Houve efeito significativo $(\mathrm{P} \leq 0,05)$ da interação amostra*julgador para os oito atributos avaliados. A existência de interação indica que pelo menos um julgador avaliou as amostras ou uma amostra de forma diferente da equipe. As amostras diferiram entre si $(\mathrm{P} \leq 0,05)$ pelo teste $\mathrm{F}$ para todos os atributos avaliados, indicando que a adição de CPS alterou os atributos de aparência, aroma, textura e sabor das sobremesas lácteas sem gordura (Tabela 2).

A figura 1 é uma projeção dos resultados obtidos da análise de componentes principais (ACP) para as amostras estudadas. $\mathrm{O}$ primeiro componente principal (CP I) explicou 99,66\% da variação dos dados, sendo suficiente para discriminar as amostras quanto aos seus atributos sensoriais. A separação espacial das quatro formulações sugeriu a formação de dois grupos distintos, um grupo formado pelas amostras controle e CPS1,5 e outro formado por CPS3,0 e CPS4,5 (Figura 1a). Na figura 1b, têm-se as correlações entre os atributos sensoriais e os dois primeiros componentes principais. Nessa figura, os atributos sensoriais são representados por vetores. Todos os atributos correlacionaram-se positivamente $(\mathrm{P} \leq 0,05)$ apenas com o primeiro componente principal. Sendo assim, as formulações contendo 3,0 e 4,5\% de CPS, localizadas à direita da figura $1 \mathrm{a}$ (lado positivo do eixo horizontal), apresentaram maior intensidade dos atributos levantados. Já as formulações controle e CPS1,5, localizadas do lado esquerdo da figura 1a (lado negativo do eixo horizontal), possuíam esses atributos em menor intensidade.

Em relação ao brilho e à cor, as formulações CPS3,0 e CPS4,5 foram semelhantes, apresentando maior intensidade desses atributos. Portanto, a adição de CPS realçou a cor das sobremesas lácteas diet. Esse resultado corrobora os encontrados por ALFAIFI \& STATHOPOULOS (2010), que avaliaram o efeito da substituição da gema de ovo por isolado proteico de soro (IPS), nas concentrações de 4,5\% e $9,0 \%$ na cor de sorvete de baunilha. Esses autores reportaram que o sorvete com maior concentração de IPS apresentou maior luminosidade e cor amarela do que a amostras contendo $4,5 \%$ de IPS.

Pode-se observar que houve aumento da intensidade dos atributos firmeza, resistência ao corte, consistência e gomosidade com o aumento na concentração de CPS. Isso mostra que o CPS foi efetivo na composição da textura. Segundo ANTUNES et al. (2003), com o aumento da concentração proteica, ocorre uma modificação na textura dos géis, resultando em um aumento da firmeza e intensificando a retenção de água pela matriz. Esse comportamento é atribuído, principalmente, a ß-lactoglobulina, que é considerada o principal agente formador de gel, devido à presença de grupos sulfidrilas livres. Sendo assim, quanto maior a quantidade de concentrado proteico de soro nos níveis testados, maior foi a força necessária para romper a estrutura do gel.

Apesar de as formulações apresentarem a adição da mesma concentração de aroma de baunilha, as amostras diferiram entre si em relação aos atributos aroma e sabor de baunilha. As amostras CPS3,0 e CPS4,5 apresentaram maior intensidade desse atributo. De acordo com PRINDIVILLE et al. (2000), as proteínas do soro podem imitar a gordura em termos de textura e retenção de aroma. Segundo KERSIENE et al. (2008), ligações entre componentes do aroma e proteínas são geralmente fracas e incluem ligações reversíveis, como forças de Van der Waals, pontes de hidrogênio e interações hidrofóbicas. Sendo assim, o aroma é liberado mais facilmente. Segundo WEEL et al. (2002), a textura também pode influenciar na percepção do sabor pelo julgador, uma vez que pode haver integração dos sinais 
Tabela 2 - Resumo da ANOVA dos atributos sensoriais de sobremesa láctea diet tipo flan.

\begin{tabular}{|c|c|c|c|c|c|c|c|}
\hline \multirow{2}{*}{ Atributo } & \multirow{2}{*}{ FV } & \multirow{2}{*}{ GL } & \multirow{2}{*}{ QM } & \multicolumn{2}{|c|}{--------Versus resíduo--------- } & \multicolumn{2}{|c|}{--Versus interação------- } \\
\hline & & & & $\mathrm{F}$ & Prob. & $\mathrm{F}$ & Prob. \\
\hline \multirow{4}{*}{ Brilho } & $\mathrm{A}$ & 3 & 64,7530 & $38,87 *$ & $<0,0001$ & $2,18^{*}$ & $<0,0001$ \\
\hline & $\mathrm{J}$ & 8 & 26,1664 & 15,71 & & & \\
\hline & $\mathrm{A}^{* \mathrm{~J}}$ & 24 & 29,6923 & $17,82 *$ & $<0,0001$ & & \\
\hline & Res & 72 & 1,6660 & & & & \\
\hline \multirow{4}{*}{ Cor } & A & 3 & 370,1492 & $984,15^{*}$ & $<0,0001$ & $148,45^{*}$ & $<0,0001$ \\
\hline & $\mathrm{J}$ & 8 & 3,9171 & 10,41 & & & \\
\hline & $\mathrm{A}^{* J}$ & 24 & 2,4935 & $6,63^{*}$ & $<0,0001$ & & \\
\hline & Res & 72 & 0,3761 & & & & \\
\hline \multirow{4}{*}{ Firmeza } & A & 3 & 415,1329 & $609,16^{*}$ & $<0,0001$ & $128,99 *$ & $<0,0001$ \\
\hline & $\mathrm{J}$ & 8 & 0,5669 & 0,83 & & & \\
\hline & $\mathrm{A}^{* \mathrm{~J}}$ & 24 & 3,2183 & $4,72 *$ & $<0,0001$ & & \\
\hline & Res & 72 & 0,6815 & & & & \\
\hline \multirow{4}{*}{ Resistência ao corte } & A & 3 & 422,2942 & $682,75^{*}$ & $<0,0001$ & $147,59 *$ & $<0,0001$ \\
\hline & $\mathrm{J}$ & 8 & 0,5749 & 0,93 & & & \\
\hline & $\mathrm{A}^{* \mathrm{~J}}$ & 24 & 2,8612 & $4,63^{*}$ & $<0,0001$ & & \\
\hline & Res & 72 & 0,6185 & & & & \\
\hline \multirow{4}{*}{ Aroma baunilha } & A & 3 & 282,4674 & $376.25^{*}$ & $<0,0001$ & $39,16^{*}$ & $<0,0001$ \\
\hline & $\mathrm{J}$ & 8 & 6,8072 & 9,07 & & & \\
\hline & $\mathrm{A}^{* \mathrm{~J}}$ & 24 & 7,2134 & $9,61^{*}$ & $<0,0001$ & & \\
\hline & Res & 72 & 0,7507 & & & & \\
\hline \multirow{4}{*}{ Consistência } & A & 3 & 416,6166 & $636,96^{*}$ & $<0,0001$ & $167,18^{*}$ & $<0,0001$ \\
\hline & $\mathrm{J}$ & 8 & 2,1195 & 3,24 & & & \\
\hline & $\mathrm{A}^{* \mathrm{~J}}$ & 24 & 2,4891 & $3,81^{*}$ & $<0,0001$ & & \\
\hline & Res & 72 & 0,6541 & & & & \\
\hline \multirow{4}{*}{ Gomosidade } & A & 3 & 385,4223 & $676,29^{*}$ & $<0,0001$ & $91,78^{*}$ & $<0,0001$ \\
\hline & $\mathrm{J}$ & 8 & 6,0315 & 10,58 & & & \\
\hline & $\mathrm{A}^{* \mathrm{~J}}$ & 24 & 4,1993 & $7,37^{*}$ & $<0,0001$ & & \\
\hline & Res & 72 & 0,5699 & & & & \\
\hline \multirow{4}{*}{ Sabor baunilha } & A & 3 & 263,7672 & $227,62^{*}$ & $<0,0001$ & $26,30 *$ & $<0,0001$ \\
\hline & $\mathrm{J}$ & 8 & 11,6995 & 10,10 & & & \\
\hline & $\mathrm{A}^{* \mathrm{~J}}$ & 24 & 10,0310 & $8,66^{*}$ & $<0,0001$ & & \\
\hline & $\operatorname{Res}$ & 72 & 1,1588 & & & & \\
\hline
\end{tabular}

$\mathrm{A}=$ Amostra $\mathbf{J}=$ Julgador; $\mathrm{A} * \mathrm{P}=$ Interação Amostra versus Julgador; Res = Resíduo;

* significativo ao nível de $5 \%$ de probabilidade.

dos sentidos que atingem simultaneamente o cérebro durante ao consumo do gel (psicofísica).

Aceitabilidade sensorial

Com os dados obtidos no teste de aceitação, foi realizada a análise de mapa de preferência interno (Figuras 2a e 2b).
Para o atributo textura (Figura 2a), o primeiro componente principal (CP I) explicou 59,35\% da variação de aceitação entre as amostras e o segundo (CP II) $25,43 \%$. Os dois explicaram $83,78 \%$ da variância total dos dados de aceitação, sendo considerados suficientes para discriminar as amostras quanto à aceitação. A separação espacial das amostras indicou 


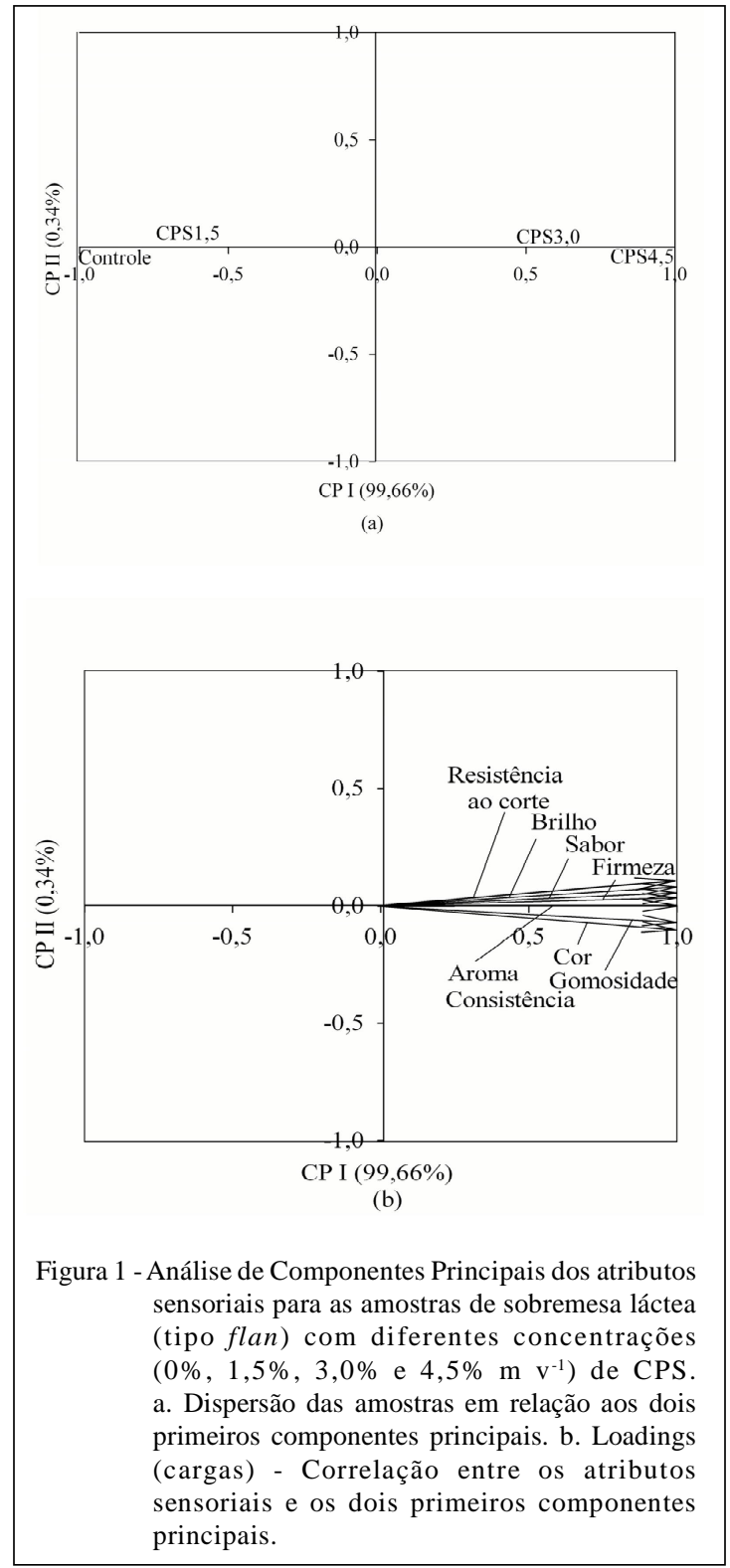

que houve a formação de quatro grupos que diferiram entre si na aceitação, quanto à textura (Figura 2a). Cada ponto na figura 2 representa a correlação entre os dados de aceitação de um consumidor e os dois primeiros componentes principais, ou seja, cada ponto está associado a um consumidor. A correlação de consumidores com pelo menos um dos componentes indica diferença na aceitação das amostras.

As amostras de sobremesa láctea sem gordura diferiram entre si quanto à aceitação pelos consumidores. No MDPREF, a maior concentração dos consumidores próximos às amostras indica que eles gostaram. Dessa forma, em relação à textura, as amostras CPS1,5 e CPS3,0 foram as mais aceitas pelos consumidores. Já a amostra controle foi a menos aceita dentre as quatro amostras avaliadas. Os consumidores relataram que esta amostra apresentava textura pouco firme e a formulação CPS4,5, apesar de ser mais consistente, tinha aspecto arenoso. Sendo assim, as formulações com valores intermediários de CPS foram as mais aceitas. Este resultado corrobora os encontrados por OLIVEIRA et al. (2004), que avaliaram a aceitabilidade sensorial de pudins (com açúcar e dietéticos) e flans comerciais. Esses autores observaram que a dureza influenciou na aceitação desses produtos. As amostras que apresentaram valores de dureza muito baixos ou muito altos tiveram menor índice de aprovação e a sobremesa com perfil de textura intermediário foi a mais aceita. 


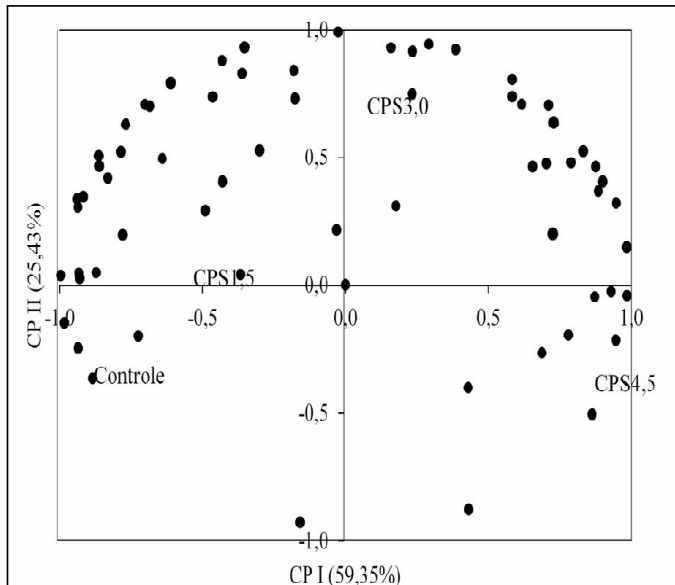

(a)

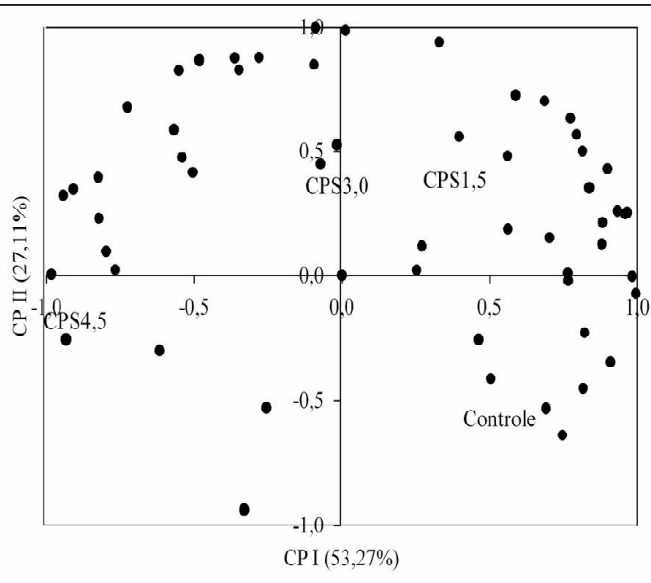

(b)

Figura 2 - Mapa de preferência interno para as quatro formulações de sobremesas lácteas (tipo flan) sem gordura com diferentes concentrações $\left(0 \%, 1,5 \%, 3,0 \%\right.$ e $\left.4,5 \% \mathrm{~m} \mathrm{v}^{-1}\right)$ de CPS em relação à textura (a) e impressão global (b). • consumidores.

Em relação à impressão global, o primeiro componente principal (CP I) explicou 53,27\% da variação dos dados e o segundo (CP II) $27,11 \%$, totalizando, portanto, $80,38 \%$ da variância entre as amostras (Figura 2b). A separação espacial das formulações para o atributo impressão global teve o mesmo comportamento obtido para a textura, ocorrendo formação de quatro grupos distintos. As formulações CPS1,5 e CPS3,0 foram as mais aceitas, enquanto a CPS4,5 apresentou menor aceitação. Segundo CAMPBELL et al. (2011) a alta concentração da proteína de soro pode influenciar negativamente na aceitação do consumidor.

A adição de até 3,0\% de CPS (CPS3,0) favoreceu a aceitabilidade da sobremesa láctea sem gordura, proporcionando características sensoriais agradáveis aos consumidores.

\section{CONCLUSÃO}

A adição de CPS altera os atributos sensoriais das sobremesas lácteas diet, de modo que a intensidade dos atributos firmeza, resistência ao corte, consistência e gomosidade aumenta com o acréscimo de CPS. A adição de CPS foi efetiva na composição da consistência das sobremesas lácteas diet, além de realçar a cor, o sabor e o aroma do produto.

A adição de 1,5\% e 3,0\% de CPS favorece a aceitabilidade pelos consumidores, constituindo excelentes opções de formulações para o novo produto. A adição de 1,5\% de CPS é economicamente mais viável para a indústria de alimentos. No entanto, a formulação contendo 3,0\% de CPS é mais interessante para os consumidores por conter maior concentração de proteínas bioativas.

Sendo assim, as sobremesas lácteas sem gordura adicionadas de 1,5 e 3,0\% de CPS mostram-se tecnologicamente viáveis para participar do mercado de produtos lácteos diet.

\section{AGRADECIMENTOS}

Ao Conselho Nacional de Desenvolvimento Científico e Tecnológico $(\mathrm{CNPq})$ e à Coordenação de Aperfeiçoamento de Pessoal de Nível Superior (CAPES), pelo apoio financeiro.

\section{COMITÊ DE ÉTICA}

Registro no 50717257515/2009, obedecendo, conforme descrito, os requisitos necessários para sua publicação.

\section{REFERÊNCIAS}

ALFAIFI, M.S.; STATHOPOULOS, C.E. Effect of egg yolk substitution by sweet whey protein isolate on texture, stability and colour of Gelato-style vanilla ice cream. International Journal of Dairy Technology, v.63, n.4, p.593-598, 2010. Disponível em: <http://onlinelibrary.wiley.com/doi/10.1111/ j.1471-0307.2010.00609.x/pdf>. Acesso em: 26 set. 2011. doi: 10.1111/j.1471-0307.2010.00609.x.

ANTUNES, A.E.C. et al. Perfil de textura e capacidade de retenção de água de géis ácidos de concentrado proteico de soro de leite. Ciência e Tecnologia de Alimentos, v.23, p.183189, 2003. Disponível em: <http://www.scielo.br/ scielo.php?script =sci_arttext \& pid=S 0101 20612003000400034>. Acesso em: 12 ago. 2011. doi: 10.1590/S0101-20612003000400034. 
CAMPBELL, R.E. et al. The effect of starter culture and annatto on the flavor and functionality of whey protein concentrate. Journal of Dairy Science, v.94, n.3, p.11851193, 2011. Disponível em: <http://www.sciencedirect.com/ science/article/pii/S0022030211000737>. Acesso em: 24 set. 2011. doi: $10.3168 /$ jds.2010-3789.

COCHRAN, W.G.; COX, G.M. Diseños experimentales. 7.ed. México: Editorial Trillas, 1981. 661p.

DE WIJK, R.A. et al. Perceived creaminess of semi-solid foods. Trends in Food Science \& Technology, v.17, p.412-422, 2006. Disponível em: <http://www.sciencedirect.com/science/ article/pii/S0924224406000562>. Acesso em: 24 set. 2011. doi: 10.1016/j.tifs.2006.02.005.

GONZÁLEZ-TOMÁS, L. et al. Rheology, flavour release and perception of low-fat dairy desserts. International Dairy Journal, v.18, p.858-866, 2008. Disponível em: <http:// www.sciencedirect.com/science/article/pii/ S0958694607001872>. Acesso em: 06 set. 2011. doi: 10.1016/ j.idairyj.2007.09.010.

ISO 11036:1994. Sensory analysis: methodology - Texture profile. Geneva: International Organization for Standardization, 1994.

KAPOOR, R.; METZGER, L.E. Evaluation of salt whey as an ingredient in processed cheese. Journal of Dairy Science, v.87, p.1143-1150, 2004. Disponível em: <http://www.sciencedirect.com/ science/article/pii/S0022030204732622>. Acesso em: 26 set. 2011. doi: 10.3168/jds.S0022-0302(04)73262-2.

KERSIENE, M. et al. Interactions between flavour release and rheological properties in model custard desserts: effect of starch concentration and milk fat. Food Chemistry, v.108, p.11831191, 2008. Disponível em: <http://www.sciencedirect.com/ science/article/pii/S0308814607011533>. Acesso em: 26 set. 2011. doi: 10.1016/j.foodchem.2007.11.011.

LIZARRAGA, M.S. et al. Rheological behavior of whey protein concentrate and -carrageenan aqueous mixtures. Food Hydrocolloids, v.20, p.740-748, 2006. Disponível: <http:// www.sciencedirect.com/science/article/pii/ S0268005X05001608>. Acesso em: 12 ago. 2011. doi: 10.1016/j.foodhyd.2005.07.007.
MEILGAARD, M. et al. Sensory evaluation techniques. 4.ed. Boca Raton: Taylor \& Francis, 2006. 448p.

MINIM, V.P.R. Análise sensorial: estudos com consumidores. 2.ed. Viçosa: UFV, 2010. 308p.

NIKAEDO, P.H.L. et al. Caracterização tecnológica de sobremesas lácteas achocolatadas cremosas elaboradas com concentrado proteico de soro e misturas de gomas carragena e guar. Brazilian Journal of Pharmaceutical Sciences, v.40, n.3, p. 397-404, 2004. Disponível em: <http://www.scielo.br/ pdf/rbcf/v40n3/16.pdf >. Acesso em: 06 set. 2011. doi: 10.1590/ S1516-93322004000300016.

OLIVEIRA, A.P.V. et al. Aceitação de sobremesas lácteas dietéticas e formuladas com açúcar: teste afetivo e mapa de preferência interno. Ciência e Tecnologia de Alimentos, v.24, n.4, p.627-633, 2004. Disponível em: <http:// www.scielo.br/pdf/cta/v24n4/a25v24n4.pdf >. Acesso em: 10 ago. 2011. doi: 10.1590/S0101-20612004000400025.

PRINDIVILLE, E.A. et al. Effect of milk fat, cocoa butter, and whey protein fat replacers on the sensory properties of lowfat and nonfat chocolate ice cream. Journal Dairy Science, v.83, p.2216-2223, 2000. Disponível em: <http:// www.sciencedirect.com/science/article/pi / S0022030200751058>. Acesso em: 06 set. 2011. doi: 10.3168/ jds.S0022-0302(00)75105-8.

STONE, H.; SIDEL, J.L. Sensory evaluation practices. London: Academic, 1993. 337p.

TÁRREGA, A.; COSTELL, E. Colour and consistency of semisolid desserts: Instrumental and sensory measurements. Journal of Food Engineering, v.78, p.655-661, 2007. Disponível em: <http://www.sciencedirect.com/science/article/pii/ S026087740500751X>. Acesso em: 12 ago. 2011. doi: 10.1016/j.jfoodeng.2005.11.003.

WEEL, K.G.C. et al. Flavor release and perception of flavored whey protein gels: perception is determined by texture rather than by release. Journal of Agriculture Food Chemistry, v.50, p.5149-5155, 2002. Disponível em: <http://pubs.acs.org/ doi/abs/10.1021/jf0202786>. Acesso em: 26 set. 2011. doi: $10.1021 /$ jf0202786. 